
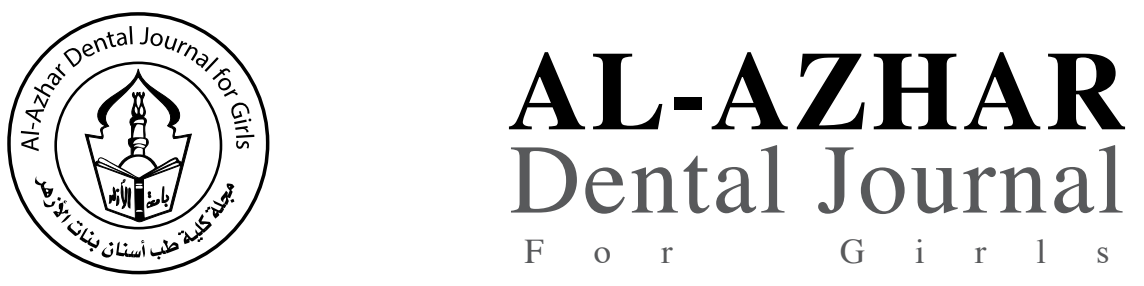

The Official Publication of The Faculty of Dental Medicine For Girls, Al-Azhar University Cairo, Egypt.

ADJ-for Grils, Vol. 4, No. 3, July (2017) — PP. 215:222

\title{
Surgical Templates for Dental Implant Positioning; Current Knowledge and Clinical Perspectives
}

\author{
Mohammed Zaheer Kola ${ }^{(1)}$, Altaf H Shah ${ }^{(1)}$,Hesham S Khalil ${ }^{(2)}$, Nehad Mohammed H Harby ${ }^{(3)}$, \\ Ahmed Mahmoud Rabah ${ }^{(4)}$, Seham Ali Sabra ${ }^{(4)}$ and Deepti Raghav ${ }^{(5)}$
}

Codex : 26/1707

dentaljournal.forgirls@yahoo.com

\section{KEYWORDS}

Dental implants,

surgical templates,

surgical procedure, stent

\begin{abstract}
Dental implants have been used in a variety of different forms for many years. Since the mid-20th century, there has been an increase in interest in the implant process for the replacement of missing teeth. Branemark was one of the initial pioneers who applied scientifically based research techniques to develop an endosseous implant that forms an immobile connection with bone. The need for a dental implant to completely address multiple physical and biological factors imposes tremendous constraints on the surgical and handling protocol. Metallic dental implants have been successfully used for decades, but they have serious shortcomings related to their bony union and the fact that their mechanical properties do not match those of bone. However, anatomic limitation and restorative demands encourage the surgeon to gain precision in planning and surgical positioning of dental implants. Ideal placement ofthe implant facilitates the establishment of favorable forces on the implants and the prosthetic component as well as ensures an aesthetic outcome. Therefore, it is advisable to establish a logical continuity between the planned restoration and the surgical phases, it is essential to use a transfer device that for sure increases the predictability of success. The surgical guide template is fabricated by a dental technician after the presurgical restorative appointments that primarily include determination of occlusal scheme and implant angulations. Here, authors genuinely attempted to review the evolution and clinical applicability of surgical templates used in the placement of dental implants.
\end{abstract}

1. Departments of Prosthodontics and 1Preventive Dental Sciences, College of Dentistry, Salman bin Abdulaziz University, Al-Kharj, KSA (Saudi Arabia),

2. Department of Maxillofacial Surgery, College of Dentistry, King Saud University, Al- Riyadh, KSA (Saudi Arabia),

3. Department of Removable Prosthodontics, Al-Azhar university, College of Dentistry, Cairo branch for boys (Egypt)

4. Department of Prosthodontics, Alfarabi College of Dentistry, Al-Riyadh, KSA (Saudi Arabia),

5. Department of Prosthodontics, Shree Bankey Bihari Dental College and Research Centre, Ghaziabad, India 


\section{INTRODUCTION}

Osseointegrated implants are a practical alternative to traditional prosthodontics; however, designing an implant-supported prosthesis with function and esthetics is a challenge. High accuracy in planning and execution of surgical procedures is important in securing a high-success rate without causing iatrogenic damage ${ }^{[1]}$ This can be achieved by computed tomography (CT), three-dimensional implant planning software, image-guided template production techniques, and computer-aided surgery. The success of implant therapy depends primarily on appropriate treatment planning and properly performed implant placement surgery. Misaligned placement of the implant is a very common dilemma that frequently complicates the clinical laboratory procedures intended for the fabrication of superstructures. This actually necessitates a close collaboration of prosthodontists and surgeons to work jointly as a team that will facilitate the precise preparation of the surgical stent or surgical guide. By definition, a stent is an appliance used for radiographic evaluation of height and width of the available bone during treatment planning for implant placement or during surgical procedures to provide the site for optimum implant placement. The use of surgical guides to implant placement will undoubtedly assist the surgeon to create biomechanically sound implant locations. It also dictates to the surgeon about the implant body placement that offers the best combination of support for the repetitive forces of occlusion, esthetics and hygiene requirements.

The desired configuration of the surgical stent is determined by the prescribed prosthesis. The surgical template dictates to the surgeon the implant body placement that offers the best combination of (1) support for the repetitive forces of occlusion, (2) esthetics, (3) hygiene requirements. ${ }^{[2,3]}$

Literature evidenced various methods of fabrication for the surgical template. The requirements are more relevant than the options of fabrication.
The template should be stable and rigid when in the correct position. If the arch treated has remaining teeth, the template should fit over and/or around enough teeth to stabilize it in position. If the arch has no remaining teeth, the template should extend onto un-reflected soft tissue regions. In this way, the template may be used after the soft tissues have been reflected from the implant site. ${ }^{[4,5]}$ The ideal angulation for implant insertion should be determined on the diagnostic wax-up, and the template should relate this position during surgery. This requires at least two reference points for each implant. For that purpose, the surgical guide must be elevated above the edentulous bone. The distance between two points located, respectively, on the occlusal surface (central fossa or incisal edge) of the planned abutment crown and the crest of the ridge represents about $8 \mathrm{~mm} \cdot{ }^{[6,7]}$ As a result, these two points of reference can be joined by a line that represents the path of ideal implant insertion. The ideal angulations are perpendicular to the occlusal plane and parallel to the most anterior abutment (natural or implant) joined to the implant. Other ideal requirements of the surgical template include size, surgical asepsis, transparency, and the ability to revise the template as indicated. The template should not be bulky and difficult to insert or obscure surrounding surgical landmarks. ${ }^{[8]}$

The surgical template must not contaminate a surgical field during bone grafts or implant placement. It should be transparent. In this way, the bony ridge and drills can be observed more easily when the template is in place. The surgical template should be related to the ideal facial contour. Many edentulous ridges have lost facial bone, and the template can determine the amount of augmentation required for implant placement or support of the lips and face. The surgical template may be used in conjunction with a bone graft, and later the same template may be used for insertion of implants and again for implant uncovery. A sturdy template permits re-sterilization and use for several procedures. ${ }^{[9-11]}$ Here, the authors have genuinely attempted to 
review the evolution and recent advances in the fabrication of surgical templates used in the placement of dental implants. This paper also provides a general summary of the state of the art in the dental implant template and explores possible advantages for further improvements.

\section{METHODS OF LITERATURE SEARCH}

The present epoch is an era of information and technology wherein internet has certainly revolutionized the literature search methodology related to medical science. Now, we have a number of internet-based tools that help in text mining and the retrieval of other information in seconds. Several internet-based popular search engines are Google, Yahoo, and scholarly search bibliographic databases such as PubMed, Medline Plus, Cochrane, Ebsco, Science Direct, Hinari, WebMD, IndMed, Embase, and textbooks were searched until December 2013 using Medical Subject Headings (MeSH; PubMed) based keywords such as "Dental implants", "Surgical templates," "surgical procedure," "stent." The search was limited to reviews, systematic researches, and meta-analyses in various dental journals published over the last 30 years in English. A total of 112 articles was identified, however, after examining the titles and abstracts, this number was finally condensed to 51 articles.

\section{Implant Surgical Template; Technical and Practical Considerations}

Dental implant has emerged as a novel rehabilitative option for missing teeth in last two decades, however, the inadvertent association of most surgical and prosthetic complications with inappropriate diagnosis and implant placement has also been documented. The success of dental implants in the treatment of patients is directly related to patient evaluation and precise treatment planning. As we are aware of, earlier dentists were predominantly intended to put implants where the maximum amount of bone was present, with less regard to placement of final definitive restoration. Even an inconsequen- tial discrepancy in comparison to ideal placement causes serious complications in fabrication of final prostheses. While the oral cavity is a relatively restricted space, a high degree of accuracy in placement of the implant is very important for success of the prostheses. ${ }^{[12]}$ This can be achieved by means of a surgical guide which provides adequate information regarding implant placement and at the time of surgery, it fits onto the existing dentition or on to the edentulous space.

A surgical template is the collaborative union of the guiding cylinders and the contact surface. The contact surface fits either on an element of a patient's gums or the patient's jaw. Cylinders within the drill guides assist in transferring the plane by orienting the drill in the exact location and direction. ${ }^{[13]}$ The implant has to be placed such that the bottom and sides are covered fully by bone or bone-replacement material. This must be accompanied with the preservation of adjacent vital structures. Hence, the final positioning of the implant has to be compatible with the intended final prosthodontic restoration.

\section{Historical Background with Review of Literature}

Glossary of prosthodontic terms, define surgical template as a guide used to assist in proper surgical placement and angulations of dental implants. [14] The main objective of the surgical template is to direct the implant drilling system and provide accurate placement of the implant according to the surgical treatment plan. To precisely transfer the plan to the operative site, customized conventional radiographic or computer image-guided surgical templates have become the treatment of choice. Stumpel was among the initial workers who thought of the usage of surgical stents. On the basis of the amount of the surgical restriction offered by the surgical guide templates, his research ended up with the identification of basic three-fabrication design concepts; (1) nonlimiting design, (2) partially limiting design, (3) completely limiting design. ${ }^{[15,16]}$ Nonlimiting designs only give an initial indication to the surgeon as to where the proposed prosthesis 
is in relation to the selected implant site. This design fails to emphasize on the correct angulations of the drill, thus, may result in the too much flexibility in the final positioning of the implant. Engelman et al. showed a technique in which the guide pin hole was drilled through a clear vacuum-formed matrix. However, the angulations were actually determined by the use of adjacent and opposing teeth. ${ }^{[9]}$ Later on, it was realized that these templates may serve as imaging indicators during the surgical phase of implant. These radiographic cross checking measures not only confirm the final positioning of the implant, but also confirm about the relative parallelism with adjacent and opposing dentitions.

Adrian et al. used auto polymerizing acrylic resin to fabricate radiographic cum surgical template. He molded lead foil over the maxillary and mandibular incisors and used lateral cephalogram to cross verify related parameters ${ }^{[17]}$ Tarlow employed the use of acrylic resin duplicate denture wherein he adapted vacuum-formed thermoplastic matrix (0.02 inch) over duplicate denture. Such designing dictates accurate implant location and angulations, with minimal interference to surgical access. ${ }^{[18]}$ Espinosa Marino et al. showed the first clinical use of heat polymerizing acrylic resin in fabrication of the surgical template particularly for partially missing situations. To make it radio-opaque on CT, they applied dual-curing composite resin mixed with colored chalk. ${ }^{[8]}$ Stellino et al. demonstrated acrylic resin provisional fixed restorations with the use of gutta parcha as redio-opaque marker. ${ }^{[19]}$ This is particularly useful as an alternative for removable radiologic template where a provisional fixed restoration bridges the implant site. Pesun and Gardner used vacuum-formed thermoplastic matrix to adapt over diagnostic model. ${ }^{[20]}$ Takeshita et al. were the first to introduce the concept of mixing acrylic resin with radio-opaque material to fabricate surgical template (instead of pure acrylic resin). They meshed barium sulate powder with acrylic resin in 4:1 ratio. ${ }^{[21]}$ Sicilia et al. used orthodontic wires and auto polymerizing acrylic resin while Minoretti et al. used vacuum-formed thermoplastic matrix or auto-polymerizing acrylic resin to fabricate template. [22,23] The partially limiting design allows only the first drill for osteotomy wherein the remaining osteotomy and implant placement is finished freehand by the surgeon. This design philosophy basically follows the initial fabrication of a radiographic template, which is then converted into a surgical guide template following radiographic evaluation. $\mathrm{Ku}$ and Shen applied vacuum-formed thermoplastic matrix filled with auto polymerizing resin acrylic resin where the use to remove the marker with carbide bur later ${ }^{[24]}$ This designed is employed in single implant therapy or short-span implant-supported prostheses. Becker and Kaiser, Cehreli et al. used vacuum-formed thermoplastic matrix (0.020 inch) and orthodontic resin. They showed that this methodology construct very precise surgical guide resulting in a functional and aesthetically pleasing restoration. This was shown to be very valuable in placing implants in posterior maxillary region with poor bone density. ${ }^{[25-27]}$ Almog et al. used auto polymerizing resin with vacuum formed thermoplastic matrix and lead strip ( $2 \mathrm{~mm}$ ) vertically on the lingual/palatal wall of the buccal access groove. The clinical results of this template were questionable as there was more error encountered in the bucco-lingual placement of implant. ${ }^{[28]}$ Completely limiting design restricts, all of the instruments used for the osteotomy in a bucco-lingual and mesio-distal plane. Moreover, the addition of drill stops limits the depth of the preparation, and thus, the positioning of the prosthetic table of the implant. Adrian et al. later on introduced a simple technique to fabricate a surgical guide on mounted diagnostic models of patient's mouth. He also used these mounted models to determine whether sufficient space exists for fixed cantilevered implant prosthesis ${ }^{[17]}$ Conversely, Cehreli suggested the fabrication of a bilaminar dual-purpose stent that facilitates implant placement with improved verification of implant positioning. ${ }^{[26]}$ The outer lamina is designed for use in the CT evaluation using radio-opaque markers. Ku and Shen presented a simple method of fabricating a vacuum-formed 
matrix filled with clear acrylic resin and a gutta-percha marker. The matrix can be used as not only a radio-opaque marker for evaluation but also a surgical guide during the surgical stage for single implant therapy. ${ }^{[24]}$ Afterward, Solow showed that a radiographic surgical template can facilitate consultation with a surgeon and patient, when implant-supported restorations are planned. A template that provides radiographic evaluation of the implant site and precise or modified surgical placement is presented. ${ }^{[29]}$ Akça et al. described a modified surgical stent that serves as a guide to proper mesio-distal paralleling of dental implants. ${ }^{[30]}$

\section{Evolution of Computer Aided Advanced Radiographic Templates}

In spite of the fact that the conventional technique of template fabrication is widely used, it has certain unavoidable drawbacks that actually led the development of advanced fabrication technique. The surgical templates are fabricated primarily on dental casts or models, which is a rigid, nonfunctional surface without the knowledge of underlying soft tissue resiliency and bone topography. ${ }^{[13,31]}$ Moreover, the anatomical landmarks are not exactly located, it does not confirm the underlying blood supply. ${ }^{[32-34]}$ Hence, the overall approach is two-dimensional. Even the panoramic radiography has its diagnostic limitations, such as expansion and distortion, setting error, positional artefacts, and there is no information regarding the dimension of bone in bucco-lingual direction. The final treatment outcome may be greatly influenced and thereby more chances of miss-positioning the implants during placement. Even if conventional surgical templates allow the placement of the implant guiding, they do not provide exact three-dimensional guidance. ${ }^{[35,36]}$

\section{Computer-Aided Design/Computer- Assisted Manufacturing-Based Surgical Guide}

To overcome the limitations associated with conventional radiographic surgical template, computer-generated surgical template have been evolved. computer-aided design/computer-assisted manufacturing (CAD/CAM) technology uses data from CT scan to plan implant rehabilitation. ${ }^{[37,38]}$ The CT images are converted into data that are recognized by a CT imaging and planning software. This software then transfers this presurgical plan to the surgery site using stereo-lithographic drill guides. Utilizing the latest scanning, CAD/CAM and manufacturing technologies, the dental team is able to develop individualized dental restoration with high accuracy and precision of fit. ${ }^{[39-41]}$ According to the original Branemark protocol, the time period for the osseo-integration of an implant, prior to restoration, in preparation for loading was between 3 and 6 months, depending on implant position and bone quality. CAD/CAM-based surgical guides offer many advantages. Accuracy of CAD/CAM technology in dental implant planning and predictable transfer of the presurgical plan to the surgical site have been documented. Stereo-lithography, a rapid prototyping technology, a newer outcome in dentistry allows the fabrication of surgical guides from three-dimensional computer-generated models for precise placement of the implants. ${ }^{[22-45]}$ The surgical templates fabricated by this technology are preprogrammed with individual depth, angulations, mesio-distal, and labio-lingual positioning of the implant..$^{[46,47]}$

\section{Advantages}

1. Precise placement of implants

2. Conservation of anatomic structures

3. Three-dimensional technology allows precise evaluation of anatomic points such as the size of the maxillary sinus in the upper jaw and location of the alveolar nerve in the lower jaw

4. Precise analysis of osseous topography

5. Provides information about size, direction, and bone location for accurate positioning of implants

6. High observed accuracy of $0.1 \mathrm{~mm}$ 
7. Reduced surgical exposure time

8. Less invasive, flapless surgery, and, therefore, less chance of swelling

9. Less postoperative strain on dentist and patient

10. Transparency of material which allows seeing through the model

11. To summarize stereolithography fabrication process.

12. A CT scan procedure is performed with a radiographic template fabricated using radio-opaque marker in place.

\section{DISADVANTAGES}

1. Lack of visibility and tactile control during the surgical procedure

2. Insufficient mouth opening jeopardizes surgical procedure

3. A risk of damage to vital anatomical structures.

\section{CONCLUSION}

Improvements in surgical reconstructive methods, as well as increased prosthetic demands, require a highly accurate diagnosis, planning, and placement. Identification of the bony anatomy with respect to the teeth, prior to surgery, allows the clinician to place implants in areas where the implant-bone interface can be maximized, and the prosthetic result is optimized. As discussed earlier, the completely limiting design is considered far superior design concept, most clinicians still adopt the partially limiting design due to its cost-effectiveness and credibility in the field; in addition, it has been observed that most clinicians use surgical guide templates that are based on cross-sectional imaging to facilitate accurate planning and guidance during the surgical phase. Computer-aided planning and image-guided surgery can be carried out, when implant positioning is to be precisely executed, and when safe positioning of implants with optimal use of available bone, and whenever a CT scan is recommended as a diagnostic means evidence-based research still needs to be conducted to evaluate the applications of the completely limiting design and its effect on the treatment outcome in oral implantology.

\section{REFERENCES}

1. Misch CE. Contemporary Implant Dentistry. $3^{\text {rd }}$ ed., St. Louis.: Mosby Publications; 2007.

2. Petrikowski CG, Pharoah MJ, Schmitt A. Presurgical radiographic assessment for implants. J Prosthet Dent 1989;61:59-64.

3. Babbush CA. Dental Implants: The Art and Science. 1st ed. Philadelphia: WB Saunders Company; 2001.

4. Christopher HJ. The use of radio-opaque templates for predictable implant placement. Quintessence Int 1995; 26:609-2.

5. Burns DR, Crabtree DG, Bell DH. Template for positioning and angulation of intraosseous implants. J Prosthet Dent 1988;60:479-83.

6. Zinner ID, Small SA, Panno FV. Presurgical prosthetics and surgical templates. Dent Clin North Am 1989;33:619-33.

7. Borrow JW, Smith JP. Stent marker materials for computerized tomograph-assisted implant planning. Int $\mathbf{J}$ Periodontics Restorative Dent 1996;16:60-7.

8. Espinosa Marino J, Alvarez Arenal A, Pardo Ceballos A, Fernandez Vazquez JP, Ibaseta Diaz G. Fabrication of an implant radiologic-surgical stent for the partially edentulous patient. Quintessence Int 1995;26:111-4.

9. Engelman MJ, Sorensen JA, Moy P. Optimum placement of osseointegrated implants. J Prosthet Dent 1988;59:467-73.

10. Edge MJ. Surgical placement guide for use with osseointegrated implants. J Prosthet Dent 1987;57:719-22.

11. Kraut RA. Interactive radiologic diagnosis and case planning for implants. Dent Implantol Update 1994; 5:49-55.

12. Drill guides for every case scenario: SurgiGuide Cookbook. Available from: http://www.materialisedental. com/materialise/view/en/2395185SurgiGuide+dental+dri ll+guide+Cookbook. html. [Last cited on 2013 Dec 05].

13. Brief J, Edinger D, Hassfeld S, Eggers G. Accuracy of image-guided implantology. Clin Oral Implants Res 2005;16:495-501. 
14. The glossary of prosthodontic terms. J Prosthet Dent 2005; 94 :

15. Stumpel LJ 3rd. Cast-based guided implant placement: A novel technique. J Prosthet Dent 2008;100:61-9.

16. Misch CE, Dietsh-Misch F. Diagnostic casts, preimplant prosthodontics, treatment prostheses, and surgical templates. In: Misch CE, editor. Contemporary Implant Dentistry. 2nd ed. St Louis, Mo: Mosby; 1999. p. 135-50.

17. Adrian ED, Ivanhoe JR, Krantz WA. Trajectory surgical guide stent for implant placement. J Prosthet Dent 1992;67:687-91.

18. Tarlow JL. Fabrication of an implant surgical stent for the edentulous mandible. J Prosthet Dent 1992;67:217-8.

19. Stellino G, Morgano SM, Imbelloni A. A dual-purpose, implant stent made from a provisional fixed partial denture. J Prosthet Dent 1995;74:212-4.

20. Pesun IJ, Gardner FM. Fabrication of a guide for radiographic evaluation and surgical placement of implants. J Prosthet Dent 1995;73:548-52.

21. Takeshita F, Tokoshima T, Suetsugu T. A stent for presurgical evaluation of implant placement. J Prosthet Dent 1997;77:36-8.

22. Sicilia A, Noguerol B, Cobo J, Zabalegui I. Profile surgical template: A systematic approach to precise implant placement. A technical note. Int J Oral Maxillofac Implants 1998;13:109-14.

23. Minoretti R, Merz BR, Triaca A. Predetermined implant positioning by means of a novel guide template technique. Clin Oral Implants Res 2000;11:266-72.

24. $\mathrm{Ku} \mathrm{YC,} \mathrm{Shen} \mathrm{YF.} \mathrm{Fabrication} \mathrm{of} \mathrm{a} \mathrm{radiographic} \mathrm{and} \mathrm{surgical}$ stent for implants with a vacuum former. J Prosthet Dent 2000;83:252-3.

25. Becker CM, Kaiser DA. Surgical guide for dental implant placement. J Prosthet Dent 2000;83:248-51.

26. Cehreli MC, Aslan Y, Sahin S. Bilaminar dual-purpose stent for placement of dental implants. J Prosthet Dent 2000;84:55-8.

27. Cehreli MC, Calis AC, Sahin S. A dual-purpose guide for optimum placement of dental implants. J Prosthet Dent 2002;88:640-3.

28. Almog DM, Torrado E, Meitner SW. Fabrication of imaging and surgical guides for dental implants. J Prosthet Dent 2001;85:504-8.
29. Solow RA. Simplified radiographic-surgical template for placement of multiple, parallel implants. J Prosthet Dent 2001;85:26-9.

30. Akça K, Iplikçioglu H, Cehreli MC. A surgical guide for accurate mesiodistal paralleling of implants in the posterior edentulous mandible. J Prosthet Dent 2002;87:233-5.

31. Lal K, White GS, Morea DN, Wright RF. Use of stereolithographic templates for surgical and prosthodontic implant planning and placement. Part I. The concept. J Prosthodont 2006;15:51-8.

32. Widmann G, Bale RJ. Accuracy in computer-aided implant surgery - a review. Int J Oral Maxillofac Implants 2006;21:305-13.

33. Windhorn RJ. Fabrication and use of a simple implant placement guide. J Prosthet Dent 2004;92:196-9.

34. Al-Harbi SA, Verrett RG. Fabrication of a stable surgical template using staged tooth extraction for immediate implant placement. J Prosthet Dent 2005;94:394-7.

35. Ramasamy M, Giri, Raja R, Subramonian, Karthik, Narendrakumar R. Implant surgical guides: From the past to the present. J Pharm Bioallied Sci 2013;5:S98-102.

36. D’Souza KM, Aras MA. Types of implant surgical guides in dentistry: A review. J Oral Implantol 2012;38:643-52.

37. Arfai NK, Kiat-Amnuay S. Radiographic and surgical guide for placement of multiple implants. J Prosthet Dent 2007;97:310-2.

38. Wat PY, Pow EH, Chau FS, Leung KC. A surgical guide for dental implant placement in an edentulous jaw. J Prosthet Dent 2008;100:323-5.

39. Oh WS, Saglik B. Use of a thermoplastic vacuum-formed matrix for secure engagement of an implant surgical template. J Prosthet Dent 2008;100:326-7.

40. Nikzad S, Azari A. A novel stereolithographic surgical guide template for planning treatment involving a mandibular dental implant. J Oral Maxillofac Surg 2008;66:1446-54.

41. Holst S, Blatz MB, Eitner S. Precision for computer-guided implant placement: Using 3D planning software and fixed intraoral reference points. J Oral Maxillofac Surg 2007;65:393-9.

42. Speetor L. Computer-aided dental implant planning. Dent Clin North Am 2008;52:761-75.

43. Jabero M, Sarment DP. Advanced surgical guidance technology: A review. Implant Dent 2006;15:135-42. 
44. Almog DM, Benson BW, Wolfgang L, Frederiksen NL, Brooks SL. Computerized tomography-based imaging and surgical guidance in oral implantology. J Oral Implantol 2006;32:14-8.

45. Valente F, Schiroli G, Sbrenna A. Accuracy of computer-aided oral implant surgery: A clinical and radiographic study. Int J Oral Maxillofac Implants 2009; 24:234-42.
46. Horwitz J, Zuabi O, Machtei EE. Accuracy of a computerized tomography-guided template-assisted implant placement system: An in vitro study. Clin Oral Implants Res 2009;20:1156-62.

47. Komiyama A, Klinge B, Hultin M. Treatment outcome of immediately loaded implants installed in edentulous jaws following computer-assisted virtual treatment planning and flapless surgery. Clin Oral Implants Res 2008;19:677-85. 